\title{
Antifungal efficacy of Azadirachta indica (neem) - An in vitrostudy
}

\author{
Srinidhi Surya Raghavendra ${ }^{1}$, Ketaki Dattatray Balsaraf ${ }^{1}$
}

${ }^{1}$ Sinhgad Dental College \& Hospital, School of Dentistry, Department of Conservative Dentistry \& Endodontics, Pune, Maharashtra, India.

Received for publication: June 06, 2014 Accepted: September 17, 2014

Correspondence to: Srinidhi S R

Department of Conservative Dentistry \& Endodontics Sinhgad Dental College \& Hospital, Pune,

Maharashtra, India

Phone: +91 9372342232

E-mail: srinidhi73@gmail.com

\begin{abstract}
Aim: To evaluate antimicrobial ability of neem leaf extract, $3 \%$ sodium hypochlorite $(\mathrm{NaOCl})$ and 2\% chlorhexidine (CHX) against Candida albicans. Methods: Neem leaf extract was prepared by using absolute ethanol with fresh neem leaves, filtering the extract through muslin cloth, coarse residue and filter paper. Cultures of $C$. albicans were maintained on Brain Heart Infusion broth and Agar. The antimicrobial efficacy was checked using the Agar Diffusion and the zones of inhibition were measured. The results were statistically analysed using ANOVA test. Inter-group comparison was checked using Kruskal Wallis ANOVA and Mann Whitney tests $(a=0.05)$. Results: There was statistically significant difference between the zones of inhibition seen with $3 \% \mathrm{NaOCl}$ and Neem extract with $2 \% \mathrm{CHX}(\mathrm{p}<0.05)$. There was no significant difference observed between Neem extract and $3 \% \mathrm{NaOCl}$. Conclusions: Efficacy of Neem extract is comparable to $3 \%$ $\mathrm{NaOCl}$ against $\mathrm{C}$. albicans and it is significantly better than $2 \% \mathrm{CHX}$.
\end{abstract}

Keywords: Candida albicans; chlorhexidine; sodium hypochlorite.

\section{Introduction}

Microorganisms and their by products are considered to be the primary etiologic agents in endodontic diseases ${ }^{1}$. It is evident that an infected root canal system is a unique niche for selective species of microorganisms. Endodontic therapy aims at removal of bacteria and fungi from the root canal space and to prevent re infection. The basis of success of endodontic treatment and retreatment depends on identifying and eliminating the causative factors in the development of apical periodontitis, so that healing can be achieved. The role of bacteria, fungi and their by products in the pathogenesis of apical periodontitis has been clearly established. The reduction and elimination of bacteria, fungi and their by products should be given the utmost importance towards achieving a successful endodontic therapy ${ }^{1}$. The most effective way to achieve this aim is by means of instrumentation and irrigation.

Failure during and after endodontic treatment is associated with the presence of bacteria in the root canal ${ }^{1}$. Enterococcus faecalis and Candida albicans are known to be important resistant species in infected root canals, and they may cause treatment failures ${ }^{1}$.

Chemical treatment of the root canal system can be arbitrarily divided into irrigants, rinses and inter appointment medicaments ${ }^{2}$. Sodium hypochlorite $(\mathrm{NaOCl})$ has been widely used as an irrigant since its introduction in Endodontics. $\mathrm{NaOCl}$ has been the irrigant of choice for non-surgical endodontic procedures because of its tissue dissolving ability and anti bacterial property ${ }^{3}$. However, it has many deleterious effects if pushed beyond the apex. Unpleasant taste and odor $^{4}$, toxicity ${ }^{5}$, 
resorption ${ }^{6}$, inability to remove smear layer and fully eradicate microbes from the infected canals ${ }^{5}$ are the main disadvantages of this popular irrigant. It can be used in various concentrations like $1.5 \%, 2.5 \%, 3 \%, 5.25 \%$ and $6 \%$.

Chlorhexidine gluconate ( $\mathrm{CHX})$, a synthetic cationic bisbiguanide is a broad-spectrum antimicrobial agent effective against gram positive and gram negative bacteria. It has substantivity and long lasting antimicrobial effect due to its binding with hydroxyapatite. A $0.5 \% \mathrm{CHX}$ solution can kill all yeast cells by $5 \mathrm{~min}^{6}$. However, its activity is $\mathrm{pH}$ dependent and it is toxic to human periodontal ligament (PDL) cells ${ }^{4}$.

The use of plants and plant products as medicines could be traced as far back as the beginning of human civilization. The earliest mention of medicinal use of plants in Hindu culture is found in "Rigveda". Herbs like neem and green tea might have a potential use as irrigants as they have been found to possess antimicrobial and antifungal properties $s^{5,7}$. Neem has been extensively used in ayurveda, unani and homoeopathic medicine. The literature has shown that neem (Azadirachta indica) has antimicrobial and therapeutic effects, suggesting its potential to be used as an endodontic irrigant ${ }^{7}$, but there is lack of extensive documentation or data regarding use of neem extract as an irrigant in endodontics.

The need for this study arose keeping in mind the disadvantages of conventional endodontic irrigants like $\mathrm{NaOCl}$ and $\mathrm{CHX}$. Even though they have been proven effective against $C$. albicans, we are in constant search of alternatives that has the same efficacy but without the side effects.

The purposes of this in vitro study was to compare the antimicrobial activity of $3 \% \mathrm{NaOCl}, 2 \% \mathrm{CHX}$ and neem leaf extract against $C$. albicans and to assess the antimicrobial property of neem leaf extract against $C$. albicans using the agar diffusion method.

\section{Material and methods}

The composition of the Neem leaf extract is as follows: 3\% NaOCl (Hyposept, UPS Hygienes Pvt Ltd., Mumbai, India), 2\% CHX (Asep-RC, Anabond Stedman Pharma Research, Chennai, India), absolute ethanol (Department of Oral Pathology), normal saline (0.9\% w/v, Claris Life Sciences Ltd., Ahmedabad, India), C. albicans (ATCC 10231) culture (Department of Microbiology and Pathology).

In preparation of the herbal extracts, $25 \mathrm{~g}$ of fresh neem leaves were added to $50 \mathrm{~mL}$ of absolute ethanol. Mixture was macerated for 1-2 min and then the extract was filtered through muslin cloth for coarse residue. Extraction process was repeated again using coarse residue and $25 \mathrm{ml}$ ethanol. Both the extracts were pooled together and filtered through fast filter paper. Alcohol part was removed from the extract on water bath till the volume was about $25 \mathrm{~mL}$. Extract was prepared and stored in airtight amber colored container.

For the agar diffusion test, $C$. albicans cultures were maintained on brain heart infusion (BHI) broth and agar. Cultures grown overnight at $37^{\circ} \mathrm{C}$ in brain heart infusion
(BHI) broth on a rotary shaker $(150 \mathrm{rpm})$ and bacterial growth was checked by changes in turbidity after $24 \mathrm{~h}$. To check the antimicrobial efficacy of neem leaf extract, $3 \% \mathrm{NaOCl}$ and $2 \% \mathrm{CHX}$, agar well diffusion method was performed. BHI agar plates were prepared and cultures $(200 \mathrm{~mL})$ were spread on agar plates. Wells of $6 \mathrm{~mm}$ diameter were made in the agar surfaces. Neem leaf extract, $\mathrm{NaOCl}, \mathrm{CHX}$, positive control (absolute ethanol) and negative control (normal saline) were added to the respective wells and the plates were incubated for $24 \mathrm{~h}$ at $37^{\circ} \mathrm{C}$ in an incubator. After the incubation period, plates were removed and zones of inhibition were recorded. The test was performed two times and the average values were recorded.

\section{Results}

The results were tabulated and analyzed statistically by ANOVA. Data was compiled on Excel, statistical analysis was done using SPSS software (V.17.0) (SPSS Inc., Chicago, IL, USA). For intergroup comparisons, Kruskal-Wallis ANOVA test was used, followed by Mann Whitney test for pair wise comparison (Table 1).

No statistically significant difference was observed between zone of inhibition for Neem leaf extract and 3\% $\mathrm{NaOCl}$. There was statistically significant difference between $3 \% \mathrm{NaOCl}$ and neem extract with $2 \% \mathrm{CHX}(\mathrm{p}<0.05)$.

Table 1

\begin{tabular}{lcccc}
\hline $\begin{array}{l}\text { Serial } \\
\text { Number }\end{array}$ & Groups & $\begin{array}{c}\text { Mean } \pm \\
\text { SD(in mm) }\end{array}$ & $\begin{array}{c}\text { p value of } \\
\text { KW ANOVA }\end{array}$ & $\begin{array}{c}p \text { value of } \\
\text { M.W. test }\end{array}$ \\
1 & $3 \% \mathrm{NaOCl}$ & 19.66 & & \\
2 & Neem Leaf Extract & 16.33 & & $2 \& 1=0.043^{*}$ \\
3 & $2 \% \mathrm{CHX}$ & 8.66 & $0.011^{*}$ & $2 \& 3=0.046^{*}$ \\
4 & Ethanol (control) & 8.33 & & $2 \& 4=0.046^{*}$ \\
5 & Saline (control) & - & & $2 \& 5=0.034^{*}$ \\
\hline SD $=$ Standard Deviation. ${ }^{*} \mathrm{p}<0.05=$ statistical significance. &
\end{tabular}

\section{Discussion}

Fungi are not common members of the microbiota associated with primary endodontic infections. Fungi have occasionally been found in primary root canal infections, but they seem to be more common in root-filled teeth with failed endodontic treatment. Sundqvist et al. ${ }^{2}$ found $C$. albicans in 2 out of 24 teeth with endodontic treatment failure. Pinheiro et al. ${ }^{6}$ studied the flora in 60 root-filled teeth with persisting periapical lesion. Microorganisms were isolated from 51 teeth, and Candida species from 2 teeth.

Peciuliene et $\mathrm{al}^{8}{ }^{8}$ studied the occurrence of yeasts, enteric gram-negative rods, and $\mathrm{E}$ faecalis, especially in root-filled teeth with chronic apical periodontitis. Forty teeth were included in the study and growth was detected in 33 teeth using conventional culturing methods including selective media for yeasts (TSBV and Sabouraud plates). Yeasts were isolated from 6 teeth (18\% of the culture-positive teeth). All isolates belonged to the species $C$. albicans. 
Egan et al. ${ }^{9}$ also showed that the probability to have yeasts in the root canal was 13.8 times greater, when the patient had cultivable yeasts in saliva, the difference being statistically significant. Previous root canal treatment, coronal leakage, or previous antibiotic therapy did not seem to have an association with the occurrence of yeasts. IN another study, Dutta and Kundabala ${ }^{7}$ analyzed the antimicrobial efficacy of 5 irrigants formulated from different parts of the Azadirachta indica and compared them with $2.5 \% \mathrm{NaOCl}$ and $0.2 \%$ CHX through an agar diffusion test using $C$. albicans cultures. The authors found that $\mathrm{NaOCl}$ inhibited $C$. albicans completely and the neem extract had better efficacy than CHX. An in vitro evaluation of 5 different herbal extracts as endodontic irrigants against $E$. faecalis and $C$. albicans using quantitative polymerase chain reaction revealed that neem was highly efficient to $5.25 \% \mathrm{NaOCl}$ in reducing the counts of these microorganisms within the root canals when compared with other extracts ${ }^{10}$. Bohora et al. ${ }^{11}$ compared the antibacterial efficacy of neem leaf extract and $2 \% \mathrm{NaOCl}$ against $E$. faecalis, $C$. albicans and mixed culture, and found that neem leaf extract is a viable medicament against both microorganisms and even against mixed culture. Additionally, it is a biocompatible irrigant when compared to $2 \% \mathrm{NaOCl}$.

A strong correlation has been observed between apical periodontitis and the presence of bacteria and fungi in canals; if they persist in the root canal system at the time of obturation, there is a higher risk of failure ${ }^{1,10}$. C. albicans is the second most common cause of recalcitrant infections after E. faecalis.

Fungi have been demonstrated to possess virulence attributes that may play a role in disease causation. The mechanisms believed to be involved in pathogenesis are (1) Adaptability to a variety of environmental conditions, (2) Adhesion to a variety of surfaces, (3) Production of hydrolytic enzymes like Proteinase, (4) Morphologic transition like phenotypal switching, (5) Biofilm formation ${ }^{12}$.

In this study, selective yeast media were not used. $\mathrm{NaOCl}$ and $\mathrm{CHX}$ at various concentrations have been proven effective against $C$. albicans but they have certain disadvantages as already discussed. The need is for an endodontic irrigant that can be effective against these resistant organisms while also being biocompatible.

In dentistry, Neem has been investigated due to its antimicrobial potential against oral microorganisms especially those associated with gingivitis and periodontitis ${ }^{10}$. The use of neem as an endodontic irrigant might be advantageous because it is a biocompatible antioxidant and thus not likely to cause the severe injuries to patients that might occur due to $\mathrm{NaOCl}$ accidents. Neem acts on oral microflora because of its anti-adherence activity by altering bacterial and fungal adhesion. Nimbidin and nimbolide, which are constituents of neem, have been found to possess antibacterial and antifungal properties. These components cause lysis of the bacterial and fungal cell wall ${ }^{3}$. One study concluded that Azadirachta indica is highly efficacious in the treatment of periodontal disease thus exhibiting its biocompatibility with human PDL fibroblasts. Neem is bitter in taste and can be altered by different formulations due to addition of sweeteners and flavors to increase patient compliance and acceptability ${ }^{13}$. The results obtained in the present in vitro study showed that Neem leaf extract is a viable medicament against $C$. Albicans.

In conclusion, as the global scenario is now changing towards the use of non-toxic plant products that have traditional medicinal use, extensive research and developmental work therefore can be undertaken on neem and its products for their better efficacy, biocompatibility and economics.

Under the limitations of this study, it was concluded that the efficacy of neem leaf extract against $C$. albicans is comparable to $3 \% \mathrm{NaOCl}$. Further, the action of neem extract was significantly better than that of $2 \%$ CHX. The microbial inhibition potential of neem leaf extract observed in this study opens avenues for its use as an intracanal medication. Preclinical and clinical trials are needed to evaluate biocompatibility and safety before neem can conclusively be recommended as an intracanal irrigating solution, but in vitro observation of neem effectiveness seems promising.

\section{Acknowledgements}

Study conducted as part of Indian Council of Medical Research sponsored STS (Short term studentship) project ID no: 2013-03543. The authors are grateful for their support.

\section{References}

1. Tirali RE, Turan $Y, A$ kal N, Karahan ZC. In vitro antimicrobial activity of several concentrations of $\mathrm{NaOCl}$ and Octenisept in elimination of endodontic pathogens. Oral Surg Oral Med Oral Pathol Oral Radiol Endod. 2009; 108: $117-20$

2. Sundqvist G, Figdor D, Persson S, Sjogren U. Microbiologic analysis of teeth with failed endodontic treatment and the outcome of conservative retreatment. Oral Surg Oral Med Oral Pathol. 1998; 85: 86-92.

3. Prabhakar J, Senthilkumar M, Priya MS, Mahalakshmi K, Sehgal PK, Sukumaran VG. Evaluation of antimicrobial efficacy of herbal alternatives (Triphala and Green tea polyphenols), MTAD and 5\% Sodium Hypochlorite against $E$ faecalis biofilm formed on tooth substrate: An in vitro study. J Endod. 2010; 36: 83-6.

4. Malkhassian G, Manzur AJ, Legner M, Fillery ED, Manek S, Basrani $B R$, et al. Antibacterial efficacy of MTAD final rinse and $2 \%$ Chlorhexidine gel medication in teeth with apical periodontitis: A randomized doubleblinded clinical trial. J Endod. 2009; 35: 1483-90.

5. Chang YC, Huang FM, Tai KW, Chou MY. The effect of sodium hypochlorite and chlorhexidine on cultured human periodontal ligament cells. Oral Surg Oral Med Oral Pathol Oral Radiol Endod. 2001; 92: 446-50.

6. Pinheiro ET, Gomes BP, Ferraz CC, Teixeira FB, Zaia AA, Souza Filho FJ. Evaluation of root canal microorganisms isolated from teeth with endodontic failure and their antimicrobial susceptibility. Oral Microbiol Immunol. 2003; 18: 100-3.

7. Dutta A, Kundabala M. Antimicrobial efficacy of endodontic irrigants from Azadirachta indica: An in vitro study. Acta Odontol Scand. 2013; 71: 1594-8.

8. Peciuliene V, Reynaud AH, Balciuniene I, Haapasalo M. Isolation of yeasts and enteric bacteria in root filled teeth with chronic apical periodontitis. Int Endod J. 2001; 34: 429-34.

9. Egan MW, Spratt DA, Ng YL, Lam JM, Moles DR, Gulabivala K. Prevalence of yeasts in saliva and root canals of teeth associated with apical periodontitis. Int Endod J. 2002; 35: 321-9. 
10. Vinothkumar TS, Rubin MI, Balaji L, Kandaswamy D. In vitro evaluation of 5 different herbal extracts as an antimicrobial endodontic irrigant using real time quantitative polymerase chain reaction. J Conserv Dent. 2013; 16: 167-70.

11. Bohora A, Hegde V, Kokate S. Comparison of the antibacterial efficiency of neem leaf extract and $2 \%$ sodium hypochlorite against $E$. faecalis, $C$. albicans and mixed culture - an in vitro study. Endodontology. 2010; 22: 8-12.

12. Obando-Pereda GA, Anibal PC, Furlatti VF, Hofling JF. Evidence of heterokaryon compatibility on Candida albicans biofilm. Braz J Oral Sci. 2008; 27: 1678-81.

13. Dutta A, Kundabala M. Comparative anti microbial efficacy of Azadirachta indica irrigant with standard endodontic irrigants: A preliminary study. J Conserv Dent. 2014; 17: 133-7. 